\title{
The Set of Priors Related Concepts Instrumental in Understanding Conscious Perception Begs Clarification
}

\author{
Talis Bachmann* \\ Faculty of Social Sciences, University of Tartu, Tartu, Estonia
}

Keywords: consciousness, predictive coding, prior, expectation, perception, illusory perception, hallucination

OPEN ACCESS

Edited by:

Timo Stein,

University of Amsterdam, Netherlands

Reviewed by:

Giorgio Marchetti,

Mind, Consciousness and

Language Research Center, Italy

*Correspondence:

Talis Bachmann

talis.bachmann@ut.ee

Specialty section:

This article was submitted to

Consciousness Research,

a section of the journal

Frontiers in Psychology

Received: 02 September 2019

Accepted: 18 May 2020

Published: 23 June 2020

Citation:

Bachmann T (2020) The Set of Priors Related Concepts Instrumental in Understanding Conscious Perception

Begs Clarification.

Front. Psychol. 11:1293.

doi: 10.3389/fpsyg.2020.01293
More than 20 years ago, Block (1995) famously called “consciousness" a "mongrel concept.” Indeed, the same term had been used for many different things, leading to much misunderstanding and controversy in consciousness research. As it appears, the currently massively used set of priors related concepts such as "prior," "prediction," “expectations," “attention," etc. likewise hide premises for multiple parallel interpretations of the same data or misattributions to various constituent underlying mechanisms. This makes debates and discussions less fruitful than they could be when the terminology would be more carefully used.

Let me first provide briefly the published research background for the problem. Prior information processed before an actual stimulus-event has been shown to influence whether and how this stimulus event will be explicitly perceived (Friston, 2005; Hohwy, 2013; Auksztulewicz et al., 2018; Chao et al., 2018; de Lange et al., 2018; Keller and Mrsic-Flogel, 2018; Andersen et al., 2019; Berggren and Eimer, 2019; Crawford et al., 2019; Gandolfo and Downing, 2019; Hutchinson and Barrett, 2019; Lumaca et al., 2019; Meijs et al., 2019; Pennartz et al., 2019; Stefanics et al., 2019; Whyte, 2019; Wokke and Ro, 2019; Wolfe, 2019). The effects span across facilitation, inhibition, illusory distortion, and hallucination (Buschman and Miller, 2007; Aru and Bachmann, 2017a; Powers et al., 2017; Aru et al., 2018; Brascamp et al., 2018; Corlett et al., 2018; Flounders et al., 2019; Harrison and Rideaux, 2019; Hullfish et al., 2019; Tappin and Gadsby, 2019; Tulver et al., 2019; Valton et al., 2019; Varrier et al., 2019). Influence of priors may originate from long term memory or from actual perceptual processing of the information preceding the imperative stimulus-event to be identified, recognized, or psychophysically evaluated. However, the known phenomenology and behavioral nomenclature of the effects of priors has been explained by a multitude of concepts which are not necessarily mutually exclusive and bear complex interrelations, therefore creating confusion and contradictory standpoints in the theoretical discourse of consciousness science.

To illustrate the point, in Table 1 some pairs of mutually related concepts are presented, indicating mutual overlap where it appears to be present (in this paper I restrict the discourse to research where typical trial-by-trial stimuli presentation is used and responses of participants are recorded in order to measure objective veridicality and/or subjective evaluation of the stimuli). The effects of mechanisms attributed to information processing under the umbrella of one such concept are possibly caused or partly influenced by the mechanisms covered by some other such concept. It should be clear that in order to have clear-cut crispiness and validity of interpretations of the experimental results, experimental designs must allow avoiding hidden confounds or, at least, these possible confounds must be listed in the limitations part of studies (the standard requirement to stick to one concept and avoid unexplained parallel use of different concepts for the same effect goes without saying). The large range of overlap between the underlying perceptual-cognitive mechanisms signified by the different corresponding concepts in Table $\mathbf{1}$ shows how easy it is to create scientific misunderstanding, if not invalid interpretations. 
TABLE 1 | A set of interrelated concepts referring to the hypothetical effects of prior processed information on processing of the subsequently presented information for its perception.

\begin{tabular}{|c|c|c|c|c|c|c|c|c|c|c|}
\hline & Prior & Prediction & Prime & Expectation & $\begin{array}{l}\text { Attention } \\
\text { (top-down) }\end{array}$ & $\begin{array}{c}\text { Search } \\
\text { (target-) }\end{array}$ & Pre-cue & $\begin{array}{c}\text { Set } \\
\text { (mental set) }\end{array}$ & Anticipation & $\begin{array}{l}\text { Conditioning } \\
\text { (associative) }\end{array}$ \\
\hline & 1 & 2 & 3 & 4 & 5 & 6 & 7 & 8 & 9 & 10 \\
\hline 1. Prior & 0 & $x$ & $x$ & $x$ & $x$ & $x$ & $x / e$ & $x$ & $x$ & $x$ \\
\hline 2. Prediction & $x$ & 0 & e & e & e & e & e & $x$ & $x / e$ & e \\
\hline 3. Prime & $x$ & e & 0 & e & e & e & $x / e$ & $x$ & e & $x$ \\
\hline 4. Expectation & $x$ & e & e & 0 & $x / e$ & e & e & $x / e$ & e & e \\
\hline 5. Attention (top-down) & $x$ & e & e & e & 0 & $x$ & $x$ & $x / e$ & e & e \\
\hline 6. Search target & $x$ & e & e & e & $x$ & 0 & $x / e$ & $x$ & e & e \\
\hline 7. Pre-cue & $\mathrm{x} / \mathrm{e}$ & e & $\mathrm{x} / \mathrm{e}$ & e & $x$ & $x / e$ & 0 & $x$ & e & e \\
\hline 8. Set (mental set) & $x$ & $x$ & $x$ & $\mathrm{x} / \mathrm{e}$ & $\mathrm{x} / \mathrm{e}$ & $x$ & $x$ & 0 & $x$ & $x$ \\
\hline 9. Anticipation & $x$ & $x / e$ & e & e & e & e & e & $x$ & 0 & $x / e$ \\
\hline $\begin{array}{l}\text { 10. Conditioning } \\
\text { (associative) stimulus }\end{array}$ & $x$ & e & $x$ & e & e & e & e & $x$ & $x / e$ & 0 \\
\hline
\end{tabular}

When pairs of different concepts may be used as synonyms, the respective intersection in the table rows/columns is marked by $x$. When pairs of different concepts allow to assume the possibility of an effect from one member of the pair on the other, the respective intersection is marked by e (some possible related concepts such as forecast, foresight, readiness, preparation, demand, and adaptation have been left out of the table).

For example, we encounter a synonymous use of concepts together with avoidance of use of a possible alternative causal mechanism leading to the experimental results (Blom et al., 2020). The authors reported an effect of the expected position of a subsequent stimulus on the EEG markers of representing the expected stimulus even if its sensory signals were not presented in part of the trials. They used alternatedly concepts like "prior," "prediction," "expectation," "anticipation” (our Table intersections $1 \times 2,1 \times 4,1 \times 9)$, but avoided "attention" $(4 \times \mathrm{e} 5)$, although the spatial-attention mechanism may have been either causally involved or representing a hidden confound. Rungratsameetaweemana et al. (2018) did not use "prior," but used "expectation," which was for some reason contrasted with "attention" (suggesting replacement of the Table entry $4 \times$ e5 by 0). Another example comes from Coll et al. (2020). They used frequency tagging methods to record EEG markers of processing alternative visual stimuli. Participants (with varying levels of autistic traits) were individually conditioned to expect one of the stimuli more than the other in the scrambling/unscrambling oscillating sequence. Relative weight of the expectation related top-down signals in the EEG markers decreased with increase in autistic traits. Concepts of "prediction" and "prior experience" were used $(1 \times 2)$, but "anticipation" or "conditioning" were not used $(1 \times 9,2 \mathrm{x} / \mathrm{e} 9,1$ $\times 10,2 \mathrm{e} 10)$.

Obviously, the pattern of possible confounds and hidden sources of misinterpretation becomes even more complex and intricate when we distinguish between pre-conscious (unconscious) and conscious levels of sources of the effects related to most of the table entries. Also, it is realistic to bear in mind that no single study, even if based on many experiments, would be capable of providing finalized valid explanations for priors related phenomena and behavioral/subjective regularities of effects (likewise, it has been shown that multidimensional, brainwide activity is what drives sensory-perceptual processesStringer et al., 2019). Therefore, collective research efforts are recommended, capable of disentangling the different priors related causal factors, with division of tasks well thought through and agreed upon between the participating labs (consortia). At the level of single lab efforts the main recommendation would be to use clever converging operations (orthogonal factorial design) planned so as to take apart contributions of different levels and types of priors. Some studies can be mentioned as examples of such approaches (e.g., Oxner et al., 2019; Zuanazzi and Noppeney, 2019; see also Shalev et al., 2019). Some other authors have drawn attention to additional important distinctions if we want to have reliable predictive coding related theories: a model must be able to (i) explain how the often incompatible tasks of reflecting veridicality of the actual environment and conveying meaningful context dependent information are solved within this same model (Larkum, 2013; Press et al., 2020); (ii) account for both, long term priors related effects and the effects of priors involved in ongoing processing (Aru and Bachmann, 2017b; White, 2018); (iii) in vision as well as auditory perception, one of the priority tasks for developing valid models must be to distinguish attention effects from other predictive prior effects (e.g., Aru et al., 2018; Alilović et al., 2019; Kompus et al., in press). There have been also promising attempts to differentiate between types of priors such as structural and contextual expectations (Seriès and Seitz, 2013). Yet, the task of disentangling the varieties of priors is complicated as there seems to be no general factor of the effects of priors on perception (Tulver et al., 2019). On the other hand, this may be caused just by the fact that priors is a mongrel concept.

Understandably, there could be an explosion of differentiated concepts if we admit that even some of the subordinate level concepts themselves are "mongrels" (for "attention" this is reflected in some recommendations to abandon this concept for good-Anderson, 2011; Hommel et al., 2019. Alternatively, this concept could well be taken apart-Luo and Maunsell, 2019). Yet the main call inherent in this paper remains. Therefore, I guess many would like to see that in the papers dealing with predictive coding the "mongrel" concepts will be taken apart and 
the (possible) mutual effects and levels of action of the constituent mechanisms become clearly separated and specified. But even before this, a conceptual taxonomy is in the waiting. Who could accomplish the task? We have a lot of prior knowledge about the likely candidates, or have we?

\section{AUTHOR CONTRIBUTIONS}

The author confirms being the sole contributor of this work and has approved it for publication.

\section{REFERENCES}

Alilović, J., Timmermans, B., Reteig, L. C., Van Gaal, S., and Slagter, H. A. (2019). No evidence that predictions and attention modulate the first feedforward sweep of cortical information processing. Cereb. Cortex 29, 2261-2278. doi: 10.1093/cercor/bhz038

Andersen, L. M., Overgaard, M., and Tong, F. (2019). Visual expectations change subjective experience without changing performance. Conscious. Cogn. 71, 59-69. doi: 10.1016/j.concog.2019.03.007

Anderson, B. (2011). There is no such thing as attention. Front. Psychol. 2:246. doi: 10.3389/fpsyg.2011.00246

Aru, J., and Bachmann, T. (2017a). Expectation creates something out of nothing: the role of attention in iconic memory reconsidered. Conscious. Cogn. 53, 203-210. doi: 10.1016/j.concog.2017. 06.017

Aru, J., and Bachmann, T. (2017b). In and out of consciousness: how does conscious processing (D) evolve over time? Front. Psychol. 8:128. doi: 10.3389/fpsyg.2017.00128

Aru, J., Tulver, K., and Bachmann, T. (2018). It's all in your head: expectations create illusory perception in a dual-task setup. Conscious. Cogn. 65, 197-208. doi: 10.1016/j.concog.2018.09.001

Auksztulewicz, R., Schwiedrzik, C. M., Thesen, T., Doyle, W., Devinsky, O., Nobre, A. C., et al. (2018). Not all predictions are equal: "What" and "when" predictions modulate activity in auditory cortex through different mechanisms. J. Neurosci. 38, 8680-8693. doi: 10.1523/JNEUROSCI.036918.2018

Berggren, N., and Eimer, M. (2019). The roles of relevance and expectation for the control of attention in visual search. J. Exp. Psychol. Hum. Percept. Perform. 45, 1191-1205. doi: 10.1037/xhp0000666

Block, N. (1995). On a confusion about a function of consciousness. Behav. Brain Sci. 18, 227-247.

Blom, T., Feuerriegel, D., Johnson, P., Bode, S., and Hogendoorn, H. (2020). Predictions drive neural representations of visual events ahead of incoming sensory information. Proc. Natl. Acad. Sci. U.S.A. 117, 7510-7515. doi: $10.1073 /$ pnas. 1917777117

Brascamp, J., Sterzer, P., Blake, R., and Knapen, T. (2018). Multistable perception and the role of the frontoparietal cortex in perceptual inference. Annu. Rev. Psychol. 69, 77-103. doi: 10.1146/annurev-psych-010417-0 85944

Buschman, T. J., and Miller, E. K. (2007). Top-down versus bottom-up control of attention in the prefrontal and posterior parietal cortices. Science 315, 1860-1862. doi: 10.1126/science.1138071

Chao, Z. C., Takaura, K., Wang, L., Fujii, N., and Dehaene, S. (2018). Largescale cortical networks for hierarchical prediction and prediction error in the primate brain. Neuron 100, 1252-1266. doi: 10.1016/j.neuron.2018. 10.004

Coll, M. P., Whelan, E., Catmur, C., and Bird, G. (2020). Autistic traits are associated with atypical precision-weighted integration of top-down and bottom-up neural signals. Cognition 199:104236. doi: 10.1016/j.cognition.2020.104236

Corlett, P. R., Horga, G., Fletcher, P. C., Alderson-Day, B., Schmack, K., Powers, A. R. III, et al. (2018). Hallucinations and strong priors. Trends Cogn. Sci. 23:114. doi: 10.1016/j.tics.2018.12.001

\section{FUNDING}

Eesti Teadusagentuur, Institutional Research Support grant IUT20-40-effective during submission of the first version of the manuscript.

\section{ACKNOWLEDGMENTS}

Support from Estonian Science Agency (ETAG) IUT20-40 (subaccount TSVPH14140I) was thankfully acknowledged.

Crawford, L. E., Corbin, J. C., and Landy, D. (2019). Prior experience informs ensemble encoding. Psychonomic Bull. Rev. 26, 993-1000. doi: 10.3758/s13423-018-1542-6

de Lange, F. P., Heilbron, M., and Kok, P. (2018). How do expectations shape perception? Trends Cogn. Sci. 22, 764-779. doi: 10.1016/j.tics.2018.06.002

Flounders, M. W., González-García, C., Hardstone, R., and He, B. J. (2019). Neural dynamics of visual ambiguity resolution by perceptual prior. eLife 8:e41861. doi: $10.7554 /$ eLife.41861

Friston, K. (2005). A theory of cortical responses. Philos. Trans. R. Soc. B Biol. Sci. 360, 815-836. doi: 10.1098/rstb.2005.1622

Gandolfo, M., and Downing, P. E. (2019). Causal evidence for expression of perceptual expectations in category-selective extrastriate regions. Curr. Biol. 29, 2496-2500. doi: 10.1016/j.cub.2019.06.024

Harrison, W. J., and Rideaux, R. (2019). Voluntary control of illusory contour formation. Attention Percept. Psychophys. 81, 1522-1531. doi: 10.3758/s13414-019-01678-8

Hohwy, J. (2013). The Predictive Mind. Oxford: Oxford University Press.

Hommel, B., Chapman, C. S., Cisek, P., Neyedli, H. F., Song, J. H., and Welsh, T. N. (2019). No one knows what attention is. Attention Percept. Psychophys. 81, 2288-2303. doi: 10.3758/s13414-019-01846-w

Hullfish, J., Sedley, W., and Vanneste, S. (2019). Prediction and perception: insights for (and from) tinnitus. Neurosci. Biobehav. Rev. 102, 1-12. doi: 10.1016/j.neubiorev.2019.04.008

Hutchinson, J. B., and Barrett, L. F. (2019). The power of predictions: an emerging paradigm for psychological research. Science 28, 280-291. doi: $10.1177 / 0963721419831992$

Keller, G. B., and Mrsic-Flogel, T. D. (2018). Predictive processing: a canonical cortical computation. Neuron 100, 424-435. doi: 10.1016/j.neuron.2018. 10.003

Kompus, K., Volehaugen, V., Todd, J., and Westerhausen, R. (in press). Hierarchical modulation of auditory prediction error signaling is independent of attention. Cogn. Neurosci. 1-11. doi: 10.1080/17588928.2019.1648404

Larkum, M. (2013). A cellular mechanism for cortical associations: an organizing principle for the cerebral cortex. Trends Neurosci. 36, 141-151. doi: 10.1016/j.tins.2012.11.006

Lumaca, M., Trusbak Haumann, N., Brattico, E., Grube, M., and Vuust, P. (2019). Weighting of neural prediction error by rhythmic complexity: a predictive coding account using Mismatch Negativity. Eur. J. Neurosci. 49, 1597-1609. doi: $10.1111 /$ ejn.14329

Luo, T. Z., and Maunsell, J. H. (2019). Attention can be subdivided into neurobiological components corresponding to distinct behavioral effects. Proc. Natl. Acad. Sci. U.S.A. 116, 26187-26194. doi: 10.1073/pnas.1902286116

Meijs, E. L., Mostert, P., Slagter, H. A., de Lange, F. P., and van Gaal, S. (2019). Exploring the role of expectations and stimulus relevance on stimulus-specific neural representations and conscious report. Neurosci. Conscious. 2019:niz011. doi: $10.1093 / \mathrm{nc} / \mathrm{niz} 011$

Oxner, M., Rosentreter, E. T., Hayward, W. G., and Corballis, P. M. (2019). Prediction errors in surface segmentation are reflected in the visual mismatch negativity, independently of task and surface features. J. Vision 19, 1-20. doi: $10.1167 / 19.6 .9$

Pennartz, C. M., Dora, S., Muckli, L., and Lorteije, J. A. (2019). Towards a unified view on pathways and functions of neural recurrent processing. Trends Neurosci. 42, 589-603. doi: 10.1016/j.tins.2019.07.005 
Powers, A. R., Mathys, C., and Corlett, P. R. (2017). Pavlovian conditioninginduced hallucinations result from overweighting of perceptual priors. Science 357, 596-600. doi: 10.1126/science.aan3458

Press, C., Kok, P., and Yon, D. (2020). The perceptual prediction paradox. Trends Cogn. Sci. 24, 13-24. doi: 10.1016/j.tics.2019.11.003

Rungratsameetaweemana, N., Itthipuripat, S., Salazar, A., and Serences, J. T. (2018). Expectations do not alter early sensory processing during perceptual decision-making. J. Neurosci. 38, 5632-5648. doi: 10.1523/JNEUROSCI.3638-17.2018

Seriès, P., and Seitz, A. (2013). Learning what to expect (in visual perception). Front. Hum. Neurosci. 7:668. doi: 10.3389/fnhum.2013.00668

Shalev, N., Nobre, A. C., and van Ede, F. (2019). Time for What? Breaking down temporal anticipation. Trends Neurosci. 42, 373-374. doi: 10.1016/j.tins.2019.03.002

Stefanics, G., Stephan, K. E., and Heinzle, J. (2019). Feature-specific prediction errors for visual mismatch. NeuroImage 196, 142-151. doi: 10.1016/j.neuroimage.2019.04.020

Stringer, C., Pachitariu, M., Steinmetz, N., Reddy, C. B., Carandini, M., and Harris, K. D. (2019). Spontaneous behaviors drive multidimensional, brainwide activity. Science 364, 255-255. doi: 10.1126/science.aav7893

Tappin, B. M., and Gadsby, S. (2019). Biased belief in the Bayesian brain: a deeper look at the evidence. Conscious. Cogn. 68, 107-114. doi: 10.1016/j.concog.2019.01.006

Tulver, K., Aru, J., Rutiku, R., and Bachmann, T. (2019). Individual differences in the effects of priors on perception: a multi-paradigm approach. Cognition 187, 167-177. doi: 10.1016/j.cognition.2019.03.008

Valton, V., Karvelis, P., Richards, K. L., Seitz, A. R., Lawrie, S. M., and Seriès, P. (2019). Acquisition of visual priors and induced hallucinations in chronic schizophrenia. Brain 142, 2523-2537. doi: 10.1093/brain/awz171
Varrier, R. S., Stuke, H., Guggenmos, M., and Sterzer, P. (2019). Sustained effects of corrupted feedback on perceptual inference. Sci. Rep. 9:5537. doi: 10.1038/s41598-019-41954-Z

White, P. A. (2018). Is the perceived present a predictive model of the objective present?. Visual Cogn. 26, 624-654. doi: 10.1080/13506285.2018.1530322

Whyte, C. J. (2019). Integrating the global neuronal workspace into the framework of predictive processing: towards a working hypothesis. Conscious. Cogn. 73:102763. doi: 10.1016/j.concog.2019.102763

Wokke, M. E., and Ro, T. (2019). Competitive frontoparietal interactions mediate implicit inferences. J. Neurosci. 39, 5183-5194. doi: 10.1523/JNEUROSCI.2551-18.2019

Wolfe, J. M. (2019). Visual attention: the multiple ways in which history shapes selection. Curr. Biol. 29, R155-R156. doi: 10.1016/j.cub.2019. 01.032

Zuanazzi, A., and Noppeney, U. (2019). Distinct neural mechanisms of spatial attention and expectation guide perceptual inference in a multisensory world. J. Neurosci. 39, 2301-2312. doi: 10.1523/JNEUROSCI.2873-1 8.2019

Conflict of Interest: The author declares that the research was conducted in the absence of any commercial or financial relationships that could be construed as a potential conflict of interest.

Copyright (C) 2020 Bachmann. This is an open-access article distributed under the terms of the Creative Commons Attribution License (CC BY). The use, distribution or reproduction in other forums is permitted, provided the original author(s) and the copyright owner(s) are credited and that the original publication in this journal is cited, in accordance with accepted academic practice. No use, distribution or reproduction is permitted which does not comply with these terms. 